\title{
Efektywność relacji międzyorganizacyjnej sieci onkologicznej. Konceptualizacja kategorii
}

\author{
Dr hab. inż. Aleksandra Sus, prof. UE iD \\ Uniwersytet Ekonomiczny we Wrocławiu \\ Wydział Zarządzania, Katedra Strategii i Metod Zarządzania
}

\section{Wprowadzenie}

Badania nad relacjami zachodzącymi pomiędzy organizacjami znajdują się w centrum zainteresowania tak teoretyków, jak i praktyków od ponad 25 lat. Większość prac koncentruje się na determinantach i wyróżnikach relacji w sieciach, podejmując próby wyjaśnienia zjawisk wzrostu i rozwoju układów, które ewoluowały od diad po sieci złożone $\mathrm{z}$ większej liczby elementów, tworząc różne rodzaje sieci międzyorganizacyjnych ${ }^{1}$. Z literatury poświęconej sieciom wyłaniają się dwa główne nurty rozważań teoretycznych, a mianowicie zależność zasobowa i połączona z nią perspektywa wymiany międzyorganizacyjnej oraz teoria kosztów transakcyjnych, której podstaw należy poszukiwać w zagadnieniach ekonomicznych. W obydwu można odnaleźć cele, które koncentrują się na identyfikacji antecedencji $^{2}$ i wyników współpracy sieciowej ${ }^{3}$, a także na strukturze sieci i sposobów zarządzania układami sieciowymi. Ponadto w literaturze dotyczącej sieci międzyorganizacyjnych uwaga skupia się na takich zagadnieniach jak przewagi sieci nad

1 S.P. Borgatti, P. C. Foster, The network paradigm in organizational research: A review and typology, „Journal of Management” 2003, vol. 29, no. 6, s. 991-1013; R. Krupski (red.), Zarzqdzanie przedsiębiorstwem w turbulentnym otoczeniu, Polskie Wydawnictwo Ekonomiczne, Warszawa 2005; H.B. Milward, K.G. Provan, A Manager's Guide to Choosing and Using Collaborative Networks, IBM Center for the Business of Government, Washington 2006; W. Czakon, Sieci w zarządzaniu strategicznym, Wolters Kluwer, Warszawa 2012.

2 J.S. Fu, Y. Li, The institutional antecedent to firm's interorganizational network portfolios: Evidence from China, „Public Relations Review” 2019, no. 45, s. 1-17.

3 K.G. Provan, H.B. Milward, A Preliminary Theory of Interorganizational Network Effectiveness: A Comparative Study of Four Community Mental Health Systems, „Administrative Science Quarterly"1995, no. 40, s. 1. 
układami indywidualnymi, a w ostatnim czasie na oburęczności i dynamice układów sieciowych ${ }^{4}$. Nasuwa to spostrzeżenie, iż międzyorganizacyjne układy sieciowe zaczynają być postrzegane i analizowane przez pryzmat analogii do odrębnych bytów organizacyjnych - przedsiębiorstw. Wniosek ten jest szczególnie cenny dla zespołów badawczych poszukujących problemów badawczych w naukach o zarządzaniu i jakości, otwiera się bowiem ogromne pole eksploracji i eksploatacji zagadnień teoretycznych, które - przekute w empirię - może wpłynąć na rozwój nurtu sieciowego $\mathrm{w}$ analizowanych naukach.

Niniejsze rozważania zawierają się w podstawach koncepcyjnych interdyscyplinarnego projektu badawczego pt. „Efektywność relacji w onkologicznej sieci międzyorganizacyjnej w Polsce”, realizowanego w ramach projektu „InterEkon”, finansowanego ze środków Ministra Nauki i Szkolnictwa Wyższego ${ }^{5}$. Celem naukowym wspomnianego projektu badawczego jest opracowanie modelu czynników warunkujących efektywność relacji w sieci międzyorganizacyjnej tworzonej przez wyspecjalizowane zespoły medyczne, w tzw. sieci onkologicznej. Jednym z problemów badawczych projektu jest odpowiedź na pytanie: „Jak należy interpretować efektywność relacji międzyorganizacyjnej sieci onkologicznej?”. Stanowi ono fundament badań literatury tematu przedstawiony w niniejszym opracowaniu. Zagadnienie jest o tyle skomplikowane, iż w założeniach realizowanego projektu badawczego przyjęto, że owa efektywność nie zostanie opisana przy wykorzystaniu relacji wyników do nakładów (efektywność ekonomiczna), a w ujęciu systemowym przy wykorzystaniu zasobów i relacji z otoczeniem. Argumentem przemawiającym za takim sposobem konceptualizacji efektywności w międzyorganizacyjnej sieci onkologicznej jest skoncentrowanie na celach społecznych organizacji, które tworzą ten obiekt badań. Wyeliminowanie danych finansowych spowodowało skoncentrowanie uwagi i mocy badawczej na zagadnieniach związanych z efektywnością relacji, których podstawy prezentuje niniejsze opracowanie.

Rozdział składa się z trzech logicznie powiązanych części. Część pierwszą stanowi przedstawienie konsytuacji analizy relacji w międzyorganizacyjnej sieci onkologicznej w Polsce, co w opracowaniu rozumie się jako zaprezentowanie obiektu poddanego rozważaniom teoretycznym, a następnie badaniom praktycznym. Przedstawienie jednostek szpitalnych budujących międzyorganizacyjną sieć onkologiczną w Polsce jest o tyle istotne, iż dzięki temu nabiera znaczenia argument

4 M. Ubeda-Garica, E. Claver-Cortes, B. Marco-Lajara, Toward a dynamic construction of organizational ambidexterity: Exploring the synergies between structural differentiation, organizational context, and interorganizational relations, „Journal of Business Research” 2019, https://doi.org/10.1016/j.jbusres.2019.10.051

5 Nazwa projektu „Regionalna Inicjatywa Doskonałości”, lata 2019-2022, nr projektu 15/ RID/2018/19, kwota finansowania 10721040,00 PLN. 
rezygnacji z analizy efektywności finansowej na rzecz efektywności relacji w sieci. Te zagadnienia szczegółowo zaprezentowano w drugiej części opracowania, w której uwaga została skupiona na sposobach definiowania i rozumienia efektywności w sieciach non-profit z punktu widzenia ujęcia zasobowego. Część trzecia rozdziału prezentuje próbę przedstawienia definicji efektywności relacji w międzyorganizacyjnej sieci onkologicznej.

Celem opracowania jest sprecyzowanie kategorii efektywności relacji w sieci non-profit, w ujęciu systemowym, aby wyeliminować potencjalne zastrzeżenia w późniejszych pracach badawczych.

\section{Konsytuacja relacji w międzyorganizacyjnej sieci onkologicznej w Polsce}

Analizując znaczenia kategorii kotekstu, konsytuacji i kontekstu, zwrócono uwagę na istotne różnice pomiędzy nimi6 , które wiążą się przede wszystkim z poziomem rozważań (rysunek 1).

Sposób, w jaki zostały opisane kotekst, konsytuacja i kontekst sieci międzyorganizacyjnej, wykorzystuje także analogie, o których wspomniano we wstępie - w tym przypadku o charakterze lingwistycznym, które jednak zmieniają spojrzenie na kategorię kontekstu.

Dokonując konceptualizacji obiektu badań, wykonano wiele postępowań badawczych w zakresie istniejącej teorii. Proces ten skutkuje wypracowaniem definicji sieci międzyorganizacyjnej jako dynamicznej ${ }^{7}$ struktury składającej się z węzłów, powiązanych długoterminowymi ${ }^{8}$ relacjami ${ }^{9}$, współdziałającej i realizującej,

6 Kategoria konsytuacji pojawia się w historii lingwistyki w ramach tzw. kontekstualizmu brytyjskiego, którego początki łączą się z pracami polskiego antropologa Malinowskiego i związanego z nim badacza Firtha. Kategoria jest jednym z trzech głównych rodzajów kontekstu, obok kotekstu i kontekstu kulturowego. Kotekst jest określany jako relacja pomiędzy składnikami tekstu lub tekstami. Z kolei kontekst pozajęzykowy dotyczący sytuacji określany jest mianem konsytuacji w ujęciu sytuacyjnym: kontekst sytuacyjny (i jako taki jest opisywany w niniejszym opracowaniu), lub szerzej - kontekst kulturowy. Uwarunkowania tekstowo-sytuacyjne opisuje kategoria ogólna: kontekst - za S. Przybyszewski, Kontekst w badaniach nad językiem, http://uwm.edu.pl/polonistyka/pliki/article/161/SPrzybys zewski_Kontekst.pdf (dostęp: 1.01.2020).

7 A. Jabłoński, Spójność hybrydy strategicznej w środowisku sieciowym, Wydawnictwo Difin, Warszawa 2015, s. 24.

8 H.B. Thorelli, Networks: Between markets and hierarchies, „Strategic Management Journal” 1986, vol. 7(1), s. 37.

9 D. Barney, The Network Society, Polity Press, Cambridge 2007, s. 2. 
oprócz indywidualnych, wspólne cele ${ }^{10}$, uzyskując w ten sposób efekt synergii, która łączy atuty zależności hierarchicznych i partnerskich. Wiążące się w sieć międzyorganizacyjną obiekty realizują określone zamiary strategiczne, które w zależności od istotności mogą determinować powiązania kapitałowe i organizacyjno-prawne pomiędzy uczestnikami sieci. Do opisu sieci konieczne staje się wyznaczenie jej granic, które może określać położenie i/lub cechy węzłów ${ }^{11}$.

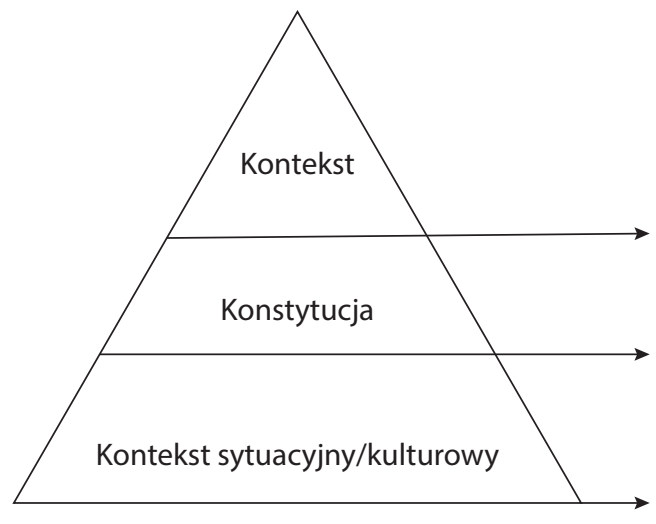

Kotekst w ujęciu sieciowym: analiza pojedynczego elementu budującego sieć; mechanizmów warunkujących jego funkcjonowanie, determinantów relacji w ujęciu indywidualnym

Konsytuacja w ujęciu sieciowym: dotyczy interakcji pomiędzy obiektami w sieci, które stanowią elementy najbliższego otoczenia sieci

Kontekst sytuacyjny/kulturowy w ujęciu sieciowym: analiza interakcji na poziomie sieć - otoczenie dalsze, ponadsytuacyjne i ponadjednostkowe relacje pomiędzy siecią i pozostałymi elementami uwikłanymi w sieć

Rysunek 1. Trzy rodzaje kontekstu w ujęciu sieci międzyorganizacyjnej

Źródto: opracowanie własne.

$\mathrm{W}$ analizowanym przypadku onkologiczną sieć międzyorganizacyjną w Polsce tworzy 17 podmiotów. Należą do nich szpitale publiczne - onkologiczne centra, z których każde znajduje się w każdym z 16 województwie w Polsce (w województwie mazowieckim znajdują się dwie takie jednostki). Prezentuje je tabela 1.

Wyróżniki relacji zachodzących pomiędzy elementami wyszczególnionymi w tabeli 1 stanowią fundament konsytuacji relacji pomiędzy elementami budującymi sieć, w konsekwencji wpływając na jej efektywność. Te zagadnienia prezentuje ostatnia część niniejszego opracowania.

10 H.B. Milward i wsp., Inter-Organizational Networks. A Review of the Literature to Inform Practice, 2014, s. 18, http://www.businessofgovernment.org/report/inter-organizational-net works-review-literature-inform-practice (dostęp: 3.01.2020).

11 M. Zdziarski, Analiza sieci, [w:] J. Niemczyk. E. Stańczyk-Hugiet, B. Jasiński (red.), Sieci międzyorganizacyjne. Wspótczesne wyzwanie dla teorii i praktyki zarzqdzania, Wydawnictwo C.H. Beck, Warszawa 2012, s. 36. 
Tabela 1. Podmioty tworzące międzyorganizacyjną sieć onkologiczną w Polsce

\begin{tabular}{|r|l|}
\hline 1 & Centrum Onkologii - Instytut im. Marii Skłodowskiej-Curie w Warszawie \\
\hline 2 & Świętokrzyskie Centrum Onkologii SP ZOZ w Kielcach \\
\hline 3 & Wielkopolskie Centrum Onkologii e Poznaniu \\
\hline 4 & Centrum Onkologii - Instytut im. Marii Skłodowskiej-Curie, Oddział w Gliwicach \\
\hline 5 & Centrum Onkologii Instytut im. Marii Skłodowskiej-Curie, Oddział w Krakowie \\
\hline 6 & Zachodniopomorskie Centrum Onkologii w Szczecinie \\
\hline 7 & $\begin{array}{l}\text { Wojewódzkie Wielospecjalistyczne Centrum Onkologii i Traumatologii im. M. Kopernika } \\
\text { w Łodzi }\end{array}$ \\
\hline 8 & $\begin{array}{l}\text { Samodzielny Publiczny ZOZ MSW z Warmińsko-Mazurskim Centrum Onkologii } \\
\text { w Olsztynie }\end{array}$ \\
\hline 9 & Kliniczny Szpital Wojewódzki nr 1 im. Fryderyka Chopina w Rzeszowie \\
\hline 10 & Szpital Specjalistyczny w Brzozowie, Podkarpacki Ośrodek Onkologiczny \\
\hline 11 & Dolnośląskie Centrum Onkologii we Wrocławiu \\
\hline 12 & Centrum Onkologii w Bydgoszczy \\
\hline 13 & Uniwersyteckie Centrum Kliniczne w Gdańsku \\
\hline 14 & Wojskowy Instytut Medyczny w Warszawie \\
\hline 15 & Beskidzkie Centrum Onkologii e Bielsku-Białej \\
\hline 16 & Szpitale Pomorskie Sp. z. o.o. w Gdyni \\
\hline 17 & Szpital Uniwersytecki im. Karola Marcinkowskiego w Zielonej Górze Sp. z o.o. \\
\hline
\end{tabular}

Źródto: opracowanie własne.

Efekt synergii, który wynika $\mathrm{z}$ funkcjonowania w medycznym układzie sieciowym, jest w głównej mierze związany z eliminacją barier o charakterze strukturalnym, okresowym i geograficznym dla realizacji wspólnego celu. Celem tym jest $\mathrm{w}$ analizowanej onkologicznej sieci międzyorganizacyjnej wypracowanie wspólnego modelu leczenia pacjentów nowotworowych w najkrótszym czasie, tzw. szybkiej ścieżki onkologicznej. Cel ten jest realizowany w wyniku transferu zasobów oraz współpracy w zakresie funkcji medycznych. Międzyorganizacyjną sieć onkologiczną w Polsce można zatem zdefiniować jako otwarty zbiór medycznych (onkologicznych) obiektów, stanowiących węzły sieci, których celem jest opieka nad pacjentami onkologicznymi ${ }^{12}$, działających na zasadzie partnerstwa, w specyficznym ekosystemie ${ }^{13}$, który z dużym prawdopodobieństwem jest identyczny dla

12 A. Sus, M. Organa, A. Sulich, Effectiveness of relations in the interorganizational oncological network in Poland - research assumptions, „Transformations in Business \& Economics” 2019, vol. 18 , issue $2 \mathrm{~B}, \mathrm{~s} .745-766$.

13 Ekosystem biznesu obejmuje powiązanie $z$ węzłem przedsiębiorstwa, a także instytucje badawcze, regulatorów, dostawców i klientów (w przypadku jednostek szpitalnych są nimi pacjenci) - W. Czakon, Sieci międzyorganizacyjne w naukach o zarzqdzaniu - w kierunku sieciowych modeli biznesu, „Studia Ekonomiczne. Zeszyty Naukowe Uniwersytetu Ekonomicznego w Katowicach" 2015, nr 217, s. 15. 
każdego węzła ${ }^{14}$. Ekosystem biznesu obejmuje nie tylko powiązane w sieci obiekty, ale także instytucje badawcze, regulatorów, dostawców urządzeń peryferyjnych itp. ${ }^{15}$ Oznacza to, że w otoczeniu każdego z analizowanych węzłów w międzyorganizacyjnej sieci onkologicznej znajdują się takie same podmioty, do których można zaliczyć: Narodowy Fundusz Zdrowia, Ministerstwo Zdrowia, jednostki i centra naukowe, firmy farmaceutyczne, apteki, dostawców sprzętu itp. Elementy te budują kontekst sytuacyjny międzyorganizacyjnej sieci onkologicznej w Polsce.

\section{Efektywność w sieci medycznej. Cele publiczne a biznesowe}

W sektorach publicznym i non-profit występuje motyw interesu publicznego, który zmienia cele i wyniki realizowane przez sieć międzyorganizacyjną w dość istotny sposób. Efektywność takiej sieci koncentruje się na realizacji celów systemowych zamiast celów organizacyjnych, co jest typowe dla sektora prywatnego. Dzieje się tak, nawet jeśli motywatory integracji i współpracy są słabe. W przypadku analizy kontekstu sytuacyjnego, czyli kluczowych grup zewnętrznych, takich jak decydenci (np. Ministerstwo Zdrowia, NFZ, jednostki naukowe) i podmioty finansujące (np. NFZ, urzędy marszałkowskie), efektywność będzie mierzona stopniem realizacji założonych celów organizacyjnych i biznesowych ${ }^{16}$. Sytuacja ma zupełnie odmienny charakter w przypadku analizy efektywności konsytuacji sieci międzyorganizacyjnej w ujęciu relacji non-profit. W takim przypadku efektywność sieci międzyorganizacyjnej wiąże się z procesem integracji organizacji uwikłanych w daną sieć. Argumentem uzasadniającym większą efektywność zintegrowanych sieci w sektorze opieki medycznej jest wzrost dostępności specjalistycznych usług zdrowotnych, zapewniających ciągłość opieki, pomimo rozproszenia geograficznego. Koordynacja zintegrowanego systemu zwiększa prawdopodobieństwo, iż wszystkie niezbędne usługi są świadczone w sieci, a klienci mają dostęp do potrzebnych specjalistów i ich kompetencji ${ }^{17}$.

Cytowana już w niniejszym opracowaniu praca Provana i Milwarda prezentuje wyniki badań nad efektywnością sieci w kontekście szpitali zajmujących się

14 Trwają badania nad elementami ekosystemu węzłów onkologicznej sieci międzyorganizacyjnej w ramach wspomnianego projektu. Ich celem jest weryfikacja tezy o koherentności elementów ekosystemów budujących każdy z dwudziestu węztów pod względem strukturalnym.

15 W. Czakon, Sieci międzyorganizacyjne..., s. 15.

16 K.G. Provan, H.B. Milward, A Preliminary Theory..., s. 3.

17 Tamże. 
leczeniem osób chorych psychicznie. Badacze zoperacjonalizowali efektywność, eksplorując związek pomiędzy strukturą sieci (koordynacją i stopniem integracji) i jej wpływem na poprawę zdrowia pacjentów. Punkt widzenia i wnioski wynikające z badań dotyczą dwóch miar sieci: ich gęstości (poziom spójności, miara stopnia, w jakim wszystkie organizacje w sieci są ze sobą połączone lub powiązane) i centralizacji (zakres, w jakim spójność jest zorganizowana wokół konkretnych punktów centralnych). Kategorią, która pojawiła się w badaniach, było zaangażowanie. Do jego pomiaru wykorzystano pięć różnych sposobów wymiany usług pomiędzy podmiotami w sieci (przesyłanych i otrzymanych poleceń usług, koordynacji spraw oraz wspólnych programów i umów o świadczenie usług). Nie była badana częstotliwość zaangażowania, z wyłączeniem identyfikacji „pewnej regularności” przesyłanych i otrzymanych zleceń pomiędzy obiektami w sieci. Ponadto sieć międzyorganizacyjna nie została zdefiniowana jako relacje pomiędzy głównymi ośrodkami medycznymi (konsytuacja), a jako relacje pomiędzy wybranymi szpitalami psychiatrycznymi i ich dostawcami/odbiorcami usług (kontekst). Z analiz wynika dość istotny wniosek dotyczący badania efektywności sieci, a mianowicie zaangażowanie w sieci było określane mianem realnego, jeśli wymiana zachodziła w obie strony relacji (np. pomiędzy podmiotem A i B). W przypadku centralizacji autorzy poddali eksploracji centralność węzłów w sieci oraz koncentrację wpływów ${ }^{18}$.

Z pewnością badanie Provana i Milwarda zmienia sposób interpretacji efektywności w sieci międzyorganizacyjnej i wykracza poza podejście zasobowe oraz koszty transakcyjne. Wprowadzając kategorie zaangażowania i wymiany, autorzy koncentrują się na innych niż organizacyjne celach sieci i zwracają swoją uwagę na zmienne systemowe, tj. czynniki determinujące integrację obiektów tworzących sieć.

W sektorze publicznym efektywność sieci jest zupełnie inną kategorią niż w układach biznesowych, ze względu na braki zasobów, duże zróżnicowanie i liczbę problemów odbiorców sieci (kategoria „klientów” brzmi niestosownie w stosunku do pacjentów sieci onkologicznej), a także ograniczoną funkcjonalność szkoleń specjalistów i stałe, niskie wynagrodzenia pracowników sieci ${ }^{19}$. Argument ten spowodował wykluczenie z procedury badawczej kryterium finansowej efektywności i skupienie uwagi na celach pozamaterialnych, tj. identyfikacji tych czynników, które wpływają na szczególny element efektywności sieci międzyorganizacyjnej, a mianowicie na relacje.

18 Tamże.

19 K.G. Provan, H.B. Milward, Do networks really work? A framework for evaluating public-sector organizational networks, „Public Administration Review” 2001, vol. 61, no. 4, s. 415. 


\section{Efektywność relacji międzyorganizacyjnej sieci onkologicznej w Polsce}

Efektywność relacji międzyorganizacyjnej sieci onkologicznej jest rozumiana jako skutek takiej kombinacji cech procesowych i strukturalnych sieci, który powoduje optymalne: wymianę (exchange) ${ }^{20}$, zaangażowanie (engagement) ${ }^{21}$ i wzajemność (reciprocity) ${ }^{22}$ pomiędzy węzłami sieci. Przedmiotami wymiany międzyorganizacyjnej, determinującej efektywność relacji, są zasoby - zarówno w ujęciu materialnym, jak i niematerialnym, a typologia wymiany skupia się na przepływach materialnych i energetycznych ${ }^{23}$. Skutkiem wymiany jest osiągnięcie wyższej efektywności niż efektywność jednostki - stanowi to jeden z motywów budowania sieci międzyorganizacyjnych ${ }^{24}$. Zaangażowanie w sieć wiąże się z pewną współzależnością od partnerów, która wynika z uwikłania się w konsekwencje negatywne (ryzyko) i pozytywne (korzyści) funkcjonowania w strukturach sieciowych. Współzależność wpływa na spójność sieci i kooperację pomiędzy tworzącymi ją elementami, których fundamentem jest zaufanie, czyli wiara, że kontrahent wypełni swoje zobowiązania ${ }^{25}$. Z kolei atrybut wzajemności stanowi kluczowy element formalnej oceny więzi przez strony relacji, który prowadzi do ich budowania, modyfikacji, ale także rozpadu. Elementami składowymi wzajemności są: zaangażowanie stron, procesy negocjacyjne przy nawiązywaniu umowy oraz jej wykonanie przez strony ${ }^{26}$.

20 T. Bar, A. Leiponen, Committee composition and networking in standard setting: the case of wireless telecommunication, „Journal of Economics \& Management Strategy”, Spring 2014, vol. 23, no. 1, s. 1-23.

$21 \mathrm{~J} . \mathrm{Ihm}$, Network measures to evaluate stakeholder engagement with nonprofit organizations on social networking sites, „Public Relations Review” 2015, no. 41, s. 501-503; R. Cross i wsp., Building engagement form the ground up: How top organizations leverage networks to drive employee engagement, „Organizational Dynamics” 2012, no. 41, s. 202-211.

22 A. Kirman i wsp., Marginal contribution, reciprocity and equity in segregated groups: Bounded rationality and self-organization in social networks, „Journal of Economics Dynamics \& Control" 2007, no. 31, s. 2085-2107; O. Pesamaa i wsp., Trust and reciprocity in building inter-personal and inter-organizational commitment in small business co-operatives, „Journal of Co-operative Organization and Management" 2013, no. 1, s. 81-92.

23 W. Czakon, Istota relacji sieciowych przedsiębiorstwa, „Przegląd Organizacji” 2005, nr 9, s. 11.

24 W. Czakon, Antecedencje wspótpracy strategicznej - poziom diady i sieci, „Prace Naukowe Uniwersytetu Ekonomicznego we Wrocławiu" 2016, no. 421, s. 84.

25 M. Odlanicka-Poczobutt, L. Knop, Rozwój i funkcjonowanie sieci w świetle podejścia endogenicznego, „Organizacja i Zarządzanie. Zeszyty Naukowe Politechniki Śląskiej” 2016, z. 89, s. 369-370.

26 P.S. Ring, A.H. Van de Ven, Developmental Process of Cooperative Interorganizational Relationships, „Academy of Management Review” 1994, vol. 19, no. 1, s. 90-118. 
Analizując efektywność międzyorganizacyjnej sieci onkologicznej w ujęciu strukturalnym, uwzględniono ważność i częstość dzielenia i transferu zasobów: informacyjnych (dane o pacjentach, kontakty bezpośrednie i pośrednie, zarówno o charakterze medycznym, jak i spoza branży lekarskiej - firmy farmaceutyczne, dostawcy sprzętu medycznego, podwykonawcy, informacje o wynikach badań medycznych, dokumentacja medyczna, a także o regulacjach formalno-prawnych, rozwiązaniach proceduralnych, umowach, rozwiązaniach diagnostyczno-prewencyjnych, o stosowanych testach diagnostycznych, terapiach celowanych, metaanalizy i inne: Big-Data ${ }^{27}$, statystyki, rozwiązania w zakresie napromieniowania techniką VMAT, wiedza o immunoterapii nowotworów, o stosowanych, spersonalizowanych szczepionkach), ludzkich (wymiana kadry lekarskiej, dzielenie się ekspertami, chirurgami i lekarzami o różnych specjalnościach: onkologami, patologami, biologami molekularnymi, diagnostami laboratoryjnymi, bioinformatykami, fizykami, radioterapeutami), sprzętowych (wyspecjalizowany sprzęt medyczny: roboty, urządzenia do radiologii, standardy diagnostyki histopatologicznej, analizy biomarkerów tkankowych) i leków (informacje o wykorzystywanych opiatach, lekach cytostatycznych, lekach na bazie kwasu walproinowego, przygotowaniu leków cytostatycznych), a także pacjentów.

Efektywność międzyorganizacyjnej sieci onkologicznej w ujęciu procesowym planuje się zbadać w kontekście realizacji czynności podstawowych i pomocniczych zgodnych z łańcuchem wartości Portera. Również i tu korzyści są analizowane pod względem ważności i częstotliwości. W przypadku realizacji funkcji pomocniczych wyodrębniono następujące potencjalne korzyści (zebrane podczas wywiadu z przedstawicielem wybranego uczestnika sieci):

- współpraca pomiędzy zespołami projektowymi;

- wymiana dobrych praktyk organizacyjnych, w tym również w zakresie systemów zarządzania, na przykład jakością i wiedzą dotyczącą zarządzania i administrowania;

- transfer wiedzy dotyczącej procesów doskonalenia zawodowego, systemów motywacyjnych, oceny, kontroli i rekrutacji pracowników;

- procedury usprawniania obsługi pacjentów;

- wspólny dostęp do nowoczesnych technologii i procedur z nimi związanych;

- transfer wiedzy o szczepionkach z immunoterapii nowotworów;

- wspólny dostęp do dostawców sprzętu medycznego, firm farmaceutycznych, sprzętu administracyjnego i pozostałych;

27 Baza do prowadzenia analizy wielowątkowej. 
- transfer wiedzy o sposobach tworzenia rezerw zasobowych, przechowywania środków medycznych, w zakresie zabiegów przedoperacyjnych, monitowania interakcji lekowych;

- doskonalenie metod i procesów leczenia i rozpisywania użytych leków;

- wymiana informacji w zakresie opieki pooperacyjnej;

- sposoby budowania wiedzy społecznej o profilaktyce nowotworowej;

- identyfikacja systemów wczesnego ostrzegania w zakresie powikłań po zabiegach medycznych i rozwiązań w zakresie tolerancji leczenia.

Zbiór korzystnych efektów współpracy między organizacjami uwikłanymi w układy sieciowe sektora opieki onkologicznej nie jest zamknięty. Stanowi raczej wstęp do szeroko zakrojonych badań empirycznych, obecnie realizowanych w Polsce, ale z zamiarem rozszerzenia działań badawczych na Europę.

\section{Podsumowanie}

Kończąc rozważania w obszarze efektywności sieci międzyorganizacyjnych, można postawić pytanie: „Czy współpraca pomiędzy węzłami w tak wrażliwej sieci międzyorganizacyjnej, jak onkologiczna, nosi znamiona serwitalizacji ${ }^{28}$, czy raczej korzyści wynikające $\mathrm{z}$ tej integracji systemowej są po prostu typowymi zaletami funkcjonowania w sieci?".

Niewątpliwe kategoria efektywności relacji a efektywności finansowej w jednostkach biznesowych jest interesującym obiektem badań i jako taka ma przełożenie na funkcjonowanie innych sieci międzyorganizacyjnych o charakterze medycznym. Przykładem takiej sieci jest sieć stomatologiczna w Polsce, której utworzenie rozwiązałoby gros problemów z transferem wiedzy i kompetencji pomiędzy jednostkami - zarówno o charakterze medycznym, jak i zarządczym. Postawione w projekcie pytania badawcze:

28 Dodawanie usług do istniejącego portfela usług określonego obiektu za S. Vandemerwe, J. Rada, Servitization of business: Adding value by adding services, „European Management Journal" 1988, vol. 6(4), s. 314-324. W analizowanym przypadku to raczej realizowanie specjalistycznych usług medycznych, których nie jest w stanie wykonać jednostka macierzysta pacjenta - tj. związana z nim geograficznie. W ten sposób integruje się usługi medyczne, co prowadzi do fundamentalnych zmian w jednostce macierzystej - T. Baines, H.W. Lightfoot, Servitization of the manufacturing firm: Exploring the operations practices and technologies that deliver advanced services, „International Journal of Operations \& Production Management" 2013, vol. 34(1), s. 2-35. Dodając bądź integrując procesy leczenia, szpitale macierzyste powinny dążyć do zmiany swoich dotychczasowych modeli biznesowych - K. Storbacka, A solution business model: Capabilities and management practices for integrated solutions, „Industrial Marketing Management” 2011, vol. 40(5), s. 699-711; K. Storbacka i wsp., Solution business models: Transformation along four continua, „Industrial Marketing Management" 2013, vol. 42(5), s. 705-716. 
- „W jaki sposób wymiana relacyjna pomiędzy węzłami sieci determinuje efektywność onkologicznej sieci międzyorganizacyjnej?”;

- „Jak zaangażowanie węzłów sieci wpływa na efektywność onkologicznej sieci międzyorganizacyjnej?";

- „Jak wzajemność węzłów sieci relacji wpływa na efektywność onkologicznej sieci międzyorganizacyjnej?";

- „Jaka jest zależność pomiędzy efektywnością onkologicznej sieci międzyorganizacyjnej a jej cechami strukturalnymi?";

- „Jaka jest zależność pomiędzy efektywnością onkologicznej sieci międzyorganizacyjnej a jej cechami procesowymi?"

nie zamykają tematu efektywności relacji w międzyorganizacyjnej sieci onkologicznej w Polsce i z powodzeniem mogą być wykorzystane jako podstawa badań longitudinalnych, których głównym celem byłaby identyfikacja wymiarów efektywności relacji. Są one także kamieniem węgielny zmian w kierunku poprawy funkcjonowania jednej z najbardziej newralgicznych dziedzin medycyny.

\section{Bibliografia}

Baines T., Lightfoot H.W., Servitization of the manufacturing firm: Exploring the operations practices and technologies that deliver advanced services, "International Journal of Operations \& Production Management" 2013, vol. 34(1), s. 2-35.

Bar T., Leiponen A., Committee composition and networking in standard setting: the case of wireless telecommunication, „Journal of Economics \& Management Strategy”, Spring 2014, vol. 23, no. 1, s. 1-23.

Barney D., The Network Society, Polity Press, Cambridge 2007.

Borgatti S.P., Foster P. C., The network paradigm in organizational research: A review and typology, „Journal of Management” 2003, vol. 29, no. 6, s. 991-1013.

Cross R., Gray P., Gerbasi A., Assimakopoulos D., Building engagement form the ground up: How top organizations leverage networks to drive employee engagement, „Organizational Dynamics" 2012, no. 41, s. 202-211.

Czakon W., Antecedencje wspótpracy strategicznej - poziom diady i sieci, „Prace Naukowe Uniwersytetu Ekonomicznego we Wroctawiu" 2016, no. 421, s. 82-89.

Czakon W., Istota relacji sieciowych przedsiębiorstwa, „Przegląd Organizacji” 2005, nr 9, s. 10-13.

Czakon W., Sieci międzyorganizacyjne w naukach o zarzq̨dzaniu - w kierunku sieciowych modeli biznesu, „Studia Ekonomiczne. Zeszyty Naukowe Uniwersytetu Ekonomicznego w Katowicach" 2015, nr 217, s. 9-18.

Czakon W., Sieci w zarzqdzaniu strategicznym, Wolters Kluwer, Warszawa 2012.

Fu J.S., Li Y., The institutional antecedent toa firm's interorganizational network portfolios: Evidence from China, „Public Relations Review” 2019, no. 45, s. 1-17.

Ihm J., Network measures to evaluate stakeholder engagement with nonprofit organizations on social networking sites, „Public Relations Review” 2015, no. 41, s. 501-503.

Jabłoński A., Spójność hybrydy strategicznej w środowisku sieciowym, Wydawnictwo Difin, Warszawa 2015. 
Kirman A., Marose S., Giansante S., Pin P., Marginal contribution, reciprocity and equity in segregated groups: Bounded rationality and self-organization in social networks, „Journal of Economics Dynamics \& Control" 2007, no. 31, s. 2085-2107.

Krupski R. (red.), Zarzqdzanie przedsiębiorstwem w turbulentnym otoczeniu, Polskie Wydawnictwo Ekonomiczne, Warszawa 2005.

Milward H.B., Provan K.G., A Manager's Guide to Choosing and Using Collaborative Networks, IBM Center for the Business of Government, Washington 2006.

Milward H.B., MacKean G., Casebeer A., Popp J., Lindstrom R., Inter-Organizational Networks. A Review of the Literature to Inform Practice, 2014, http://www.businessofgovernment.org/repo rt/inter-organizational-networks-review-literature-inform-practice (dostęp: 3.01.2020).

Odlanicka-Poczobutt M., Knop L., Rozwój i funkcjonowanie sieci w świetle podejścia endogenicznego, „Organizacja i Zarządzanie. Zeszyty Naukowe Politechniki Śląskiej” 2016, z. 89, s. 367-377.

Pesamaa O., Pieper T., Vinhas da Silva R., Black W.C., Hair Jr. J.F., Trust and reciprocity in building inter-personal and inter-organizational commitment in small business co-operatives, „Journal of Co-operative Organization and Management" 2013, no. 1, s. 81-92.

Provan K.G., Milward H.B., A Preliminary Theory of Interorganizational Network Effectiveness: A Comparative Study of Four Community Mental Health Systems, „Administrative Science Quarterly" 1995, vol. 40, no. 1, s. 1-33.

Provan K.G., Milward H.B., Do networks really work? A framework for evaluating public-sector organizational networks, „Public Administration Review” 2001, vol. 61, no. 4, s. 414-423.

Przybyszewski S., Kontekst w badaniach nad językiem, http://uwm.edu.pl/polonistyka/pliki/ar ticle/161/SPrzybyszewski_Kontekst.pdf (dostęp: 3.01.2020).

Ring P.S., Van de Ven A.H., Developmental Process of Cooperative Interorganizational Relationships, „Academy of Management Review” 1994, vol. 19, no. 1, s. 90-118.

Storbacka K., A solution business model: Capabilities and management practices for integrated solutions, „Industrial Marketing Management” 2011, vol. 40(5), s. 699-711.

Storbacka K., Windahl C., Nenonen S., Salonen A., Solution business models: Transformation along four continua, „Industrial Marketing Management” 2013, vol. 42(5), s. 705-716.

Sus A., Organa M., Sulich A., Effectiveness of relations in the interorganizational oncological network in Poland - research assumptions, „Transformations in Business \& Economics” 2019, vol. 18, issue 2B, s. 745-766.

Thorelli H.B., Networks: Between markets and hierarchies, „Strategic Management Journal” 1986, vol. 7(1), s. 37-51.

Ubeda-Garica M., Claver-Cortes E., Marco-Lajara B., Toward a dynamic construction of organizational ambidexterity: Exploring the synergies between structural differentiation, organizational context, and interorganizational relations, „Journal of Business Research” 2019, https:// doi.org/10.1016/j.jbusres.2019.10.051

Vandemerwe S., Rada J., Servitization of business: Adding value by adding services, „European Management Journal" 1988, vol. 6(4), s. 314-324.

Zdziarski M., Analiza sieci, [w:] J. Niemczyk. E. Stańczyk-Hugiet, B. Jasiński (red.), Sieci międzyorganizacyjne. Wspótczesne wyzwanie dla teorii i praktyki zarzq̨dzania, Wydawnictwo C.H. Beck, Warszawa 2012, s. 35-42. 


\section{Streszczenie}

Celem rozdziału jest konceptualizacja kategorii efektywności relacji w międzyorganizacyjnej sieci - jest on kontynuacją badań prowadzonych w sieci onkologicznej w Polsce. W opracowaniu zaprezentowano obiekt badań, argumenty przemawiające za faktem skupienia się na 16 podmiotach tworzących poddaną eksploracji sieć, a także wyróżniki efektywności sieci realizującej cele publiczne. Rozdział stanowi fundament koncepcyjny badań finansowanych ze środków wewnątrzuczelnianego projektu „InterEkon”.

Słowa kluczowe: sieć międzyorganizacyjna, sieć onkologiczna, efektywność sieci, efektywność sieci relacji, zaangażowanie, wymiana, wzajemność

\section{The effectiveness of the interorganizational relationship of the oncological network. Conceptualization of the category}

\section{Abstract}

The purpose of the article is to conceptualize the category of relationship effectiveness in an interorganizational network and it is a continuation of research conducted in the oncological network in Poland. The study presents the research object, arguments supporting the fact of focusing on 16 entities that make up the explored network, as well as distinguishing features of the efficiency of the network achieving public goals. The article is the conceptual foundation of research financed from the InterEkon project.

Keywords: inter-organizational network, oncological network, network effectiveness, relationship effectiveness, engagement, exchange, reciprocity 